\title{
Acne and Quality of Life- A Study from a Tertiary Care Centre in South India
}

\author{
Haritha Samanthula ${ }^{1}$, Madhavi Kodali ${ }^{2}$ \\ ${ }^{I}$ Department of Dermatology, Dr. Pinnamaneni Siddhartha Institute of Medical Sciences \& Research \\ Foundation, India \\ ${ }^{2}$ Departmen of Psychiatry, Dr. Pinnamaneni Siddhartha Institute of Medical Sciences \& Research Foundation, \\ India
}

\begin{abstract}
Objectives: Acne vulgaris is a chronic disease affecting the face in adolescents and adults. It has considerable psycho-social impact on Health Related Quality of Life (HRQOL).The aim of our study is to assess the impact of acne on Quality of Life.

Material and Methods: The study sample consisted of 483 consecutive patients with facial acne vulgaris. Patients who had attended the Dermatology OPD of Dr.Pinnamaneni Siddhartha Institute of Medical Sciences between November 2012 to March 2013 were included in the study. After obtaining the history, the acne was graded into mild, moderate and severe based on the type and number of lesions. Dermatology Life Quality Index(DLQI) and Cardiff Acne Disability Index(CADI) were administered on the patients to measure the Quality of Life.

Results: Majority (53.2\%) of the study population were betweeen16-20 years and the number of males was more than the number of females. Most of the patients were educated and unmarried.61.4\% of patients belonged to the urban areas \& (60.04\%) had an acne duration of $>1$ year. Severe acne was seen in $30.64 \%$ of patients and $50.35 \%$ had a moderate grade of acne. In 333 patients (68.94\%) the CADI scores were $>8$ showing a clear impact on QOL. Based on the DLQI scores $75.1 \%$ of the patients had a moderate to extremely large impairment of $Q O L$.

Conclusion: Acne has an impact on Quality of Life $(Q O L)$ and evaluation of Quality of Life helps in the better management of patients with acne.
\end{abstract}

Keywords - Acne vulgaris, Quality of Life, DLQI, CADI

\section{INTRODUCTION}

Acne is a chronic disease, involving the face affecting more than $85 \%$ of the teenagers, as well as some adults. ${ }^{1}$ Though it is considered to be merely a cosmetic problem, it is associated with considerable psychological impairment which is comparable with certain chronic diseases like asthma, epilepsy, diabetes and arthritis. ${ }^{2,3}$ Acne patients are prone to low self esteem, low confidence and social dysfunction which may lead to anxiety, depression, obsessive compulsiveness and sometimes suicidal ideation. ${ }^{4,5} \mathrm{Acne}$ affects the functional abilities of individuals ${ }^{6}$ and patients have higher rates of unemployment when compared to those without acne $e^{7}$.The majority of the studies on psycho social aspects have been conducted in US and Europe, but the impact of acne on Quality of Life( QOL) is undocumented in India. ${ }^{8,9,10,11}$

WHO defines QOL as the "individuals' perception of their position in the context of culture and value systems in which they live and in relation to their goals, expectations, standards, and concerns." ${ }^{12}$ Measurement of QOL is done with validated and reliable questionnaires like Dermatology Life Quality Index( DLQI),Acne Disability index(ADI), and Cardiff Acne Disability Index( CADI).$^{13}$

Assessing quality of life can help provide patients with better service, by acknowledging their real needs and interfering with treatment decisions. ${ }^{14}$ There are effective therapies for acne and administration of these agents can cause an improvement in quality of life and psychological health. ${ }^{15,16}$ Increased awareness and early intervention for the psychological and psychiatric sequelae of acne can benefit patients.

The aim of our study is to assess the impact of acne on Health Related Quality of Life in patients attending a tertiary care hospital.

\section{MATERIAL AND METHODS}

This study has been conducted in the OPD of the Department of Dermatology of Dr. Pinnamaneni Siddhartha Institute of Medical Sciences. The study sample consisted of 483 consecutive patients with facial acne vulgaris who had attended the Dermatology OPD over a period of 5 months between November 2012 and March 2013.

The subjects with pre-existing psychiatry disorders were excluded. The study was approved by the Institutional Ethics Committee. 
A detailed history regarding socio demographic profile, symptoms and clinical aspects was taken after obtaining consent from all the participants of the study.

Acne was graded into mild, moderate and severe based on the number, type and severity of lesions. ${ }^{17}$

Dermatology Life Quality Index (DLQI) and Cardiff Acne Disability Index (CADI) were administered on the patients to determine the impact of acne vulgaris on Health Related Quality of life(HRQOL).

DLQI is a general questionnaire for evaluation of quality of life in dermatology patients and consists of 10 questions about disease symptoms, feelings, daily activities, type of clothing, social or physical activities, exercise, job or education, interpersonal relationships, marriage relationships and treatment. Its domain is from zero(without any effect on quality of life) to 30(extremely large effect on quality of life). According to the score obtained, the effect of disease on quality of life can be divided into 5 classes which are- without effect ,small effect, moderate effect, very large effect and extremely large effect. ${ }^{18}$

CADI is a questionnaire which is specific for acne and contains 5 questions -related to the last monthabout feelings, interference with social life and interaction with the opposite gender, avoidance of public places, appearance of the skin and perceived severity of disease state. Each question is scored from 0-3 leading to a total score of 0-15. A higher score shows a very large impact on quality of life. ${ }^{19}$ In our study a CADI score $<8$ is considered to have a small effect on quality of life $\&$ a score $>8$ is considered as having a larger effect on QOL. Both the questionnaires have Persian equivalents with confirmed reliability and validity. ${ }^{20,21}$

\section{RESULTS}

The results of our study are shown in the table below which shows that majority $(53.2 \%)$ of the participants belonged to the age group 16-20 years.53.2\% were males and females constituted $46.79 \%$ of the study population. Majority of the patients were educated (74.9\%) and unmarried (68.3\%). Most of the participants $(61.4 \%)$ were from the urban areas.

290 patients $(60.04 \%)$ had an acne duration of $>1$ year. Severe acne was seen in $30.64 \%$ of patients and $50.35 \%$ had a moderate grade of acne. In 333 patients $(68.94 \%)$ the CADI scores were $>8$ showing a clear impact on QOL. Based on the DLQI scores $75.1 \%$ of the patients had a moderate to extremely large impairment of QOL.

\section{DISCUSSION}

The results of our study revealed that majority $(53.2 \%)$ of the participants belonged to the age group 1620 years which is similar to a study by Jancovic et al which showed that acne prevalence is more at the age of 16 and 17 years $^{22}$.According to Balakrishnan et al acne is a chronic disease affecting $85 \%$ of the teenagers. ${ }^{1}$

In our study the number of males was more than females which is similar to a Chinese study which reported that acne in adolescents was predominant in males and adult acne was common in females. ${ }^{23}$ In a study by Kameran Hassan Ismail the majority of the study population was constituted by females, which differs from our study. ${ }^{24}$

Our study revealed that there was a clear impact of acne on Quality of Life. It was observed that there was a large impact on QOL in $68.94 \%$ based on the CADI score. And as per the DLQI score there was a moderate to extremely large impact on the Quality of Life in $75.1 \%$ of patients. H.Safizadeh et al found that acne influenced the quality of life in $51.8 \%$ of the patients based on DLQI score. ${ }^{25}$ and Hanisha et al reported that based on the specific responses of CADI, $71.1 \%$ of the patients felt aggressive, frustrated or embarrassed as a result of having acne ${ }^{26}$.Studies have shown that impairment of Quality of Life in females was more when compared to males which could be due to the fact that adolescent girls are more vulnerable to the negative psychological effects of acne $\mathrm{e}^{27,28,29}$. The Quality of Life may also be affected by the severity of acne. Krejci Manwaring et al reported a positive correlation between acne severity and poorer quality of life. ${ }^{30}$

The majority of our study population consisted of educated and unmarried people belonging to urban areas reflecting that the Quality of Life is affected more in these patients. This could be because of factors like work atmosphere, and pattern of life in cities which make them more concerned about their appearance in the community. Hence proper counseling and psycho social support should be given to improve the Quality of Life in these patients.

\section{CONCLUSION}

Evaluation of Quality of Life in patients with acne is important as it helps in the pharmacological as well as psychological treatment of these patients in a more effective and integrated way. 
VI. FIGURES AND TABLES

Table: Socio Demographic profile, clinical features and quality of life measures in acne patients

\begin{tabular}{|c|c|c|}
\hline & No. $(n=483)$ & $\%$ \\
\hline Age & & \\
\hline $11-15$ & 41 & 8.488 \\
\hline $16-20$ & 257 & 53.2 \\
\hline $21-25$ & 120 & 24.84 \\
\hline$>25$ & 65 & 13.45 \\
\hline \multicolumn{3}{|l|}{ Sex } \\
\hline Male & 257 & 53.29 \\
\hline Female & 226 & 46.79 \\
\hline \multicolumn{3}{|l|}{ Educational Status } \\
\hline Educated & 362 & 74.94 \\
\hline Uneducated & 121 & 25.05 \\
\hline \multicolumn{3}{|l|}{ Socioeconomic status } \\
\hline Low & 68 & 14.07 \\
\hline Middle & 233 & 48.24 \\
\hline High & 182 & 37.68 \\
\hline \multicolumn{3}{|l|}{ Marital status } \\
\hline Married & 153 & 31.67 \\
\hline Unmarried & 330 & 68.32 \\
\hline \multicolumn{3}{|l|}{ Region } \\
\hline Rural & 186 & 38.5 \\
\hline Urban & 297 & 61.4 \\
\hline \multicolumn{3}{|l|}{ Duration } \\
\hline$<1 \mathrm{YR}$ & 193 & 39.95 \\
\hline$>1 \mathrm{YR}$ & 290 & 60.04 \\
\hline \multicolumn{3}{|l|}{ Acne grading } \\
\hline Mild & 109 & 22.56 \\
\hline Moderate & 243 & 50.31 \\
\hline Severe & 148 & 30.64 \\
\hline \multicolumn{3}{|l|}{ CADI } \\
\hline$<8$ & 167 & 34.57 \\
\hline$>8$ & 333 & 68.94 \\
\hline \multicolumn{3}{|l|}{ DLQI } \\
\hline No affect & 38 & 7.86 \\
\hline Little affect & 82 & 16.97 \\
\hline Moderate affect & 172 & 35.61 \\
\hline Very much affect & 138 & 28.57 \\
\hline Extremely large affect & 53 & 10.97 \\
\hline
\end{tabular}

\section{REFERENCES}

[1]. Balkrishnan R, Kulkarni AS, Cayce K, et al. Predictors of healthcare outcomes and costs related to medication use in patients with acne in the United States. Cutis 2006 Apr;77(4):251-5.

[2]. Ayer J,Burrows N.Acne: more than skin deep.Postgrad Med J 2006 Aug;82(970):500-6.

[3]. Mallon E, Newton JN, Klassen A, Stewart-Brown SL, Ryan TJ, Finlay AY. The Quality of Life in acne. A comparison with general medical conditions using generic questionnaire. Br J Dermatol 1999;140:672-6.

[4]. Tan JK. Psychological impact of acne vulgaris: Evaluating the evidence. Skin Ther Lett 2004;9:1-3,9.

[5]. Tallab TM. Beliefs, perceptions and psychological impact of acne vulgaris among patients in the Assir region of Saudi Arabia. West Afr J Med 2004;23:85-7.

[6]. Motley RJ, Finlay AY. How much disability is caused by acne? Clin Exp Dermatol 1989;14:194-8.

[7]. Cunliffe WJ. Acne and unemployment. Br J Dermatol 1986;115:386

[8]. Koo J. The psychosocial impact of acne: Patient's perceptions. J Am Acad Dermatol 1995;32:S26-30

[9]. Thomas DR. Psychosocial effects of acne. J Cutan Med Surg 2004;4:3-5

[10]. Smithard A, Glazebrook C, Williams HC. Acne prevalence, knowledge about acne and psychological morbidity in midadolescence: A community-based study. Br J Dermatol 2001;145:274-9

[11]. Walker N, Lewis-Jones MS. Quality of life and acne in Scottish adolescent school children: use of the children's dermatology life quality index (CDLQI) and the cardiff acne disability index (CADI). J Eur Acad Dermatol Venereol 2006;20:45-50 
[12]. The World Health Organization quality of life assessment (WHOQOL): Position paper from the World Health Organization. Soc Sci Med 1995;41:1403-9.

[13]. Martin AR, Lookingbill DP, Botek A, Light J, Thiboutot D, Girman CJ: Healthrelated quality of life among patients with facial acne-assessment of a new acne-specific questionnaire. Clin Exp Dermatol 2001, 26:380-385.

[14]. David SE, Ahmed Z, Salek MS, Finlay AY.Does enough quality of life discussion occur during dermatology consultations?Br J Dermatol 2005; 153:997-1000.

[15]. Chia CY, Lane W, Chibnall J, Allen A, Siegfried E. Isotretinoin therapy and mood changes in adolescents with moderate to severe acne: A cohort study. Arch Dermatol 2005; 141:557-60.

[16]. Rubinow DR, DR Peck GL, Squillace KM, Gantt GG. Reduced anxiety and depredededepression in cystic acne patients after successful treatment with oral isotretinoin. J Am Acad of DE Acad Dermatol 1987; 17:25-32

[17]. Pochi PE, Shalita AR,Strauss JS, Webster SB, WJ,Katz HI et al.Report of the consensus conference on acne classification.J AM Acad Dermatol 1991;24:495-500.

[18]. A.Y.Finlay and G.K.Khan.Dermatology Life Quality Index(DLQI):a simple practical measure for routine clinical use,Clinical and Experimental Dermatology1994; 19(3):210-216.

[19]. R.J.Motley and A.Y.Finlay,Practical use of disability index in the routine management of acne,Clinical and experimental Dermatology 1992; 17(1)1-3

[20]. S.Aghaei, M.Sodaifi, P.Jafari,N.Mazharinia, A.Y.F inlay, DLQI Scores in vitiligo:reliability and validity of the Persian version, BMC Dermatology 2004; vol 4:article 8

[21]. S.Aghaei, N.Mazharinia,P.Japari,Z,Abbasfard,The Persian version of the Cardiff Acne Disability Index:reliability and validity study,Saudi Medical Journal2006;27(1):80-82.

[22]. Jankovic S, Vukicevic J, Djordjevic S, Jankovic J, Marinkovic J. Quality of life among schoolchildren with acne: Results of a crosssectional study. Indian J Dermatol Venereol Leprol 2012;78:454-8 )

[23]. Yiwei Shen, Tinglin Wang, Cheng Zhou Prevalence of Acne Vulgaris in Chinese Adolescents and Adults: A Community-based Study of 17,345 Subjects in Six Cities: Acta Derm Venereol 2012; 92: 40-44

[24]. Ismail and MohammedAli: Quality of life in patients with acne in Erbil city. Health and Quality of Life Outcomes 2012; 10:60.

[25]. H.Safizadeh,S.Shamsi-Meymandi,A.Naeimi:Quality of Life in Iranian patients with Acne;Dermatology Research and Practice,Vol2012,Article ID 571516,4 Pages.

[26]. A. Hanisah, K. Omar, and S. A. Shah, "Prevalence of acne and its impact on the quality of life in school-aged adolescents in Malaysia," Journal of Primary Health Care,2009; 1:20-25

[27]. M.P.M.Law,AAT Chuh,A.Lee,and N.Molinari,-Acne prevalence and beyond:acne disability and its predictive factors among Chinese adolescents in Hong-Kong,Clin and Exp Dermatol 2009; 35 (1):20-25

[28]. Aktan S, Ozmen E, Sanli B. Anxiety, depression and nature of acne vulgaris in adolescents. Int J Dermatol 2000;39:354-7.

[29]. Kellett SC, Gawkrodger DJ. The psychological and emotional impact of acne and the effect of treatment with isotretinoin. Br J Dermatol 1999;140:273-82

[30]. Krejci-Manwaring J, Kerchner K, Feldman SR, et al. Social sensitivity and acne: the role of personality in negative social consequences and quality of life. Int J Psychiatry Med 2006;36(1):121-30. 